\begin{abstract}
Iranica
Abstracta Iranica Revue bibliographique pour le domaine irano-aryen

Volume 34-35-36 | 2017

Comptes rendus des publications de 2011-2013
\end{abstract}

\title{
Florence Jullien, Marie-Joseph Pierre (éds.). Les Monachismes d'Orient. Images - Échanges - Influences
}

\section{Christelle Jullien}

\section{(2) OpenEdition}

\section{Journals}

\section{Édition électronique}

URL : http://journals.openedition.org/abstractairanica/41283

DOI : 10.4000/abstractairanica.41283

ISSN : 1961-960X

Éditeur :

CNRS (UMR 7528 Mondes iraniens et indiens), Éditions de l'IFRI

\section{Référence électronique}

Christelle Jullien, «Florence Jullien, Marie-Joseph Pierre (éds.). Les Monachismes d'Orient. Images Échanges - Influences », Abstracta Iranica [En ligne], Volume 34-35-36 | 2017, document 5, mis en ligne le 15 juillet 2016, consulté le 05 octobre 2020. URL : http://journals.openedition.org/abstractairanica/ 41283 ; DOI : https://doi.org/10.4000/abstractairanica.41283

Ce document a été généré automatiquement le 5 octobre 2020.

Tous droits réservés 


\title{
Florence Jullien, Marie-Joseph Pierre (éds.). Les Monachismes d'Orient. Images - Échanges - Influences
}

\author{
Christelle Jullien
}

\section{RÉFÉRENCE}

Florence Jullien, Marie-Joseph Pierre (éds.). Les Monachismes d'Orient. Images - Échanges Influences. Hommage à Antoine Guillaumont. Actes du Colloque du Cinquantenaire de la chaire des Christianismes orientaux à l'EPHE SR, Turnhout, Brepols, 2011, 347 p. (Bibliothèque de l'École des Hautes Études. Sciences religieuses 148. Histoire et Prosopographie 6)

Cet ouvrage est le fruit d'un colloque international transdisciplinaire tenu au Collège de France le 11 juin 2008 pour marquer le cinquantenaire de la création de la chaire des "christianismes orientaux" à l'École pratique des hautes études (section des sciences religieuses). Il s'inscrit dans l'hommage particulier qui fut rendu à cette occasion aux travaux de M. Antoine Guillaumont, premier titulaire de cette chaire (1957-1981), grand spécialiste des communautés chrétiennes d'Orient et des milieux monastiques de Syrie et

d'Égypte.

Ce volume, dans un souci de transversalité, met l'accent sur les jeux d'influences réciproques que cristallise le phénomène monastique dans les différentes aires culturelles de l'Orient chrétien sur la longue durée : Sinaï, Liban, Palestine, Égypte, Éthiopie, Mésopotamie, Perse, golfe Persique... Quatre axes de réflexion structurent les réflexions : la transmission et l'élaboration de la culture monastique, dans un contexte plurilingue ; le moine et ses représentations, entre topos, reconstructions et images ; les formes de la vie monastique ; les monachismes non chrétiens (bouddhisme, question du manichéisme). Les communications ici réunies rendent compte des multiples 
interactions entre les communautés religieuses des différentes aires culturelles du Proche et Moyen-Orient et leur contribution au façonnement des sociétés dans l'Antiquité tardive, le Moyen Âge, jusqu'à nos jours.

\section{AUTEURS}

\section{CHRISTELLE JULLIEN}

CNRS, Mondes iranien et indien, Paris 